\title{
A collaborative design model to support hybrid learning environments during COVID-19
}

\author{
Thomas Cochrane, James Birt, Neil Cowie, Chris Deneen, Paul Goldacre, Vickel \\ Narayan, Lisa Ransom, David Sinfield and Tom Worthington \\ University of Melbourne, Bond University, Okayama University, University of Melbourne, University of \\ Queensland, The University of Sydney, Auckland University of Technology, Auckland University of \\ Technology, Australian National University
}

\begin{abstract}
COVID-19 has catalyzed online learning environment design across all university disciplines, including the traditionally practice-based disciplines. As we move from a rapid response triage mode of online learning towards a more sustained engagement with a mix of online and face-to- face learning environments (particularly for practice-based learning) we face some unique challenges. This concise paper explores an example of collaborative co-creation and co-design of a resource guide as a response to the challenges of COVID-19 for best practices for designing hybrid learning environments to facilitate distributed learning environments (face-to-face and remote students). The co-creative co-design of the resource guide highlights some of the identified key design principles behind facilitating distributed learning communities.
\end{abstract}

Keywords: Collaborative learning environment design, COVID-19, hybrid teaching and learning, mobile learning, Scholarship of Technology Enhanced Learning

\section{Introduction}

Designing online learning environments that replicate a large lecture environment require relatively simple substitution of pedagogical practice and are typically achieved using video streaming technologies such as Zoom. This correlates to the substitution level of the SAMR (Substitution, Augmentation, Modification, Redefinition) technology enhanced learning framework (Puentedura, 2006). In the switch to rapid online delivery brought about by the COVID-19 crisis video streaming lectures to remote students became the default go-to approach, that led to the coining of the phrase "zoom fatigue" (Lowenthal, Borup, West, \& Archambault, 2020). However, practice-based learning environments do not directly map to simple tools such as video streaming from one to many and require a significant modification or even redefinition of teaching and learning practice online. To explore how mobile learning might support a hybrid mode for practice-based learning environments during COVID19 the ASCILITE Mobile Learning special interest group collaboratively created a resource combining research and practice to form a mobile learning design guide.

\section{SOTEL}

There is an extensive body of literature based upon established good principles for designing effective online learning (Bower \& Vlachopoulos, 2018). The term Scholarship of Technology Enhanced Learning (SoTEL) updates Boyer's (1990) concept of the Scholarship of Teaching and Learning (SOTL) to integrate the use of educational technologies into scholarly informed learning designs (Haynes, 2016; Wickens, 2006). However, this body of online learning design frameworks and the link to a critical scholarship of technology enhanced learning is relatively specialist knowledge that has been the domain of the online learning designer and associated curriculum design support teams. Additionally, designing a best practice online learning experience can take many weeks (Hodges, Moore, Lockee, Trust, \& Bond, 2020). To support the rapid design of online learning during the COVID19 crisis institutional learning designers and educational technologists attempted to bridge the knowledge gap for academics new to online learning through the development of pragmatic guides that were based upon best practice and informed by online learning design theory and frameworks, for example (O'Donoghue, 2020; Smith, 2020; Zayapragassarazan, 2020). 
The rapid shift to online learning also presented access and technology ownership obstacles for academics and students who found themselves working from home in often less than ideal situations (Crawford, ButlerHenderson, Rudolph, \& Glowatz, 2020) including: a lack of a dedicated study or work space, difficulty in filtering out background audio noise from family while on synchronous video calls and lecture streams, sharing internet connectivity with an entire household, sharing computing devices with a household, and in some instances not having access to an appropriate computer or internet connection from home. One solution to several of these issues is the design of the learning environment around mobile devices such as smartphones and a redesign of the learning activities away from a reliance upon high-bandwidth teacher-centric pedagogies and technologies such as video streaming to enable student-centred collaborative learning using student-owned devices (Naciri, Baba, Achbani, \& Kharbach, 2020).

\section{Collaborative curriculum design}

Laurillard (2012) has long been an advocate for the need for collaborative curriculum design in higher education, and an advocate for the potential of technology enhanced learning and mobile learning to facilitate pedagogical innovation (Laurillard, 2007, 2008). The ASCILITE mobile learning special interest group identified their expertise in this area to collaboratively brainstorm a research-informed practical guide for designing learning environments to facilitate distributed learning communities. Based upon the established experience of the ASCILITE mobile learning SIG community of practice the SIG members spent several weeks co-creating a practical webinar series and a collection of resources for practitioners to guide the implementation of mobile learning during COVID19. This was achieved through the use of an ecology of resources to facilitate this co-design process, while at the same time modeling practice.

\section{Methodology}

\section{An ecology of resources for co-creative learning design}

The concept of a learner-centric ecology of resources was proposed by Luckin (2008), and used to inform the choice of a selection of tools to co-create and share a resource guide produced by the ASCILITE mobile learning special interest group (ASCILITEMLSIG). The guide resource and subsequent workshop/s co-design and sharing tools included:

- A collaborative PADLET for both synchronous and asynchronous brainstorming

- Zoom for synchronous discussions and weekly webinars (10 episodes between 1 May and 3 July 2020)

- Mendeley shared reference library

- Social Networks for sharing and publishing the resource guide (PADLET) and webinar archives (YouTube) using the hashtag \#ASCILITEMLSIG

While we could have chosen any number of collaborative online brainstorming platforms, PADLET provided a quick co-creative and highly visual brainstorming publication platform, that includes a variety of built-in sharing and publication modes making the platform accessible to a wide audience of academics from a variety of discipline contexts.

\section{Key themes and design principles identified from the literature}

The PADLET resource was structured around several key themes identified through the SIG members' knowledge of the literature, and a range of supporting practice ideas and resources were collated under these themes. At the time of writing the PADLET comprised 56 contributions encompassing best case examples, literature guides, embedded multimedia, tips and critiques. In this section we summarise these identified key themes for guiding best practice online learning environment design and the range of illustrative examples included. Supporting references can be found linked on the PADLET.

\section{Models and Frameworks}

- Universal Design for Learning (UDL): focus on the design of learning environments that are flexible, inclusive, and student-centred.

- Flipping the classroom: Deliver 'content' online in 'chunks' and spend the synchronous time (F2F \& online) 
on discussion and student exploration.

- Remote to Hybrid Learning: using digital to amplify, accelerate and connect learners globally.

- 3 Things to Consider When Designing Remote Teaching: student-content, student-student, and educatorstudent interactions.

Networked learning communities

- Rethink the 'classroom' and 'remote' students as forming a networked learning community.

- Examples of open networked learning.

- Using geolocation tools to build a sense of shared community across geographic boundaries.

Asynchronous strategies

- Thinking beyond Zoom: using asynchronous video to maintain connection.

- Exploring how Twitter can be utilized within the learning environment asynchronously and synchronously.

- Strategies for making instructional videos more engaging.

- Collaborative and remote multimedia production.

- Using student team management tools.

- LMS discussion forum strategies.

Synchronous strategies

- Design learning activities around the online environment for both face-to-face and remote students - think online first rather than develop or 'deliver' in two separate modes.

- Employ live back-channel discussions.

- Live streaming - focusing upon student activity: remote student live-streaming into the face-to-face classroom, and remote student peer review of physical practice.

Lab and practical class strategies

- Strategies and tips from case studies published during COVID-19

- Redesign clinical or lab-based assessment strategies as authentic student-team immersive reality scenario projects, using low-cost immersive reality development and deployment platforms.

- Employ student journals and Wikis.

Studio based strategies

- Student ePortfolios: Rethink physical studio spaces as an extension of online ePortfolios - i.e., create a 'Virtual Studio' space that both F2F \& remote students co-inhabit.

- Peer and instructor peer feedback or crits via live-streaming or asynchronous video or audio.

- Student Blogs.

Designing learner-centric ecologies of resources

- Examples of co-curated selections of mobile tools (An Ecology of Resources or EOR) that can enable remote learning and collaboration in various discipline contexts.

Resources

- Links to a variety of institutional guides, support teams, and supporting literature.

\section{Discussion}

The collaborative development of resources to guide the design and facilitation of distributed learning environments was a response to the immediate need for supporting academics from a wide range of disciplines in their rapid development of online learning environments during the COVD-19 pandemic. The reified outputs of the ASCILITEMLSIG will continue to be relevant and updated as institutions grapple with a new normal of hybrid online and face-to-face learning and teaching, particularly in reference to practice-based courses that have traditionally predominantly utilized face-to-face learning environments. Key benefits of designing practice-based learning environments to facilitate distributed learning communities include: 
- Enhancing the physical environment

- Extending and amplifying the physical environment

This involves actively interacting with the face-to-face and remote students, rather than simply streaming the face-to-face class to remote students to view passively.

\section{Designing distributed learning communities}

When designing distributed learning communities within any given context, we should begin with the question: 'What is the most authentic learning collaboration in this situation?' and think online first rather than as an addon. Instead of simply streaming a live or recorded video of a lecture to remote students the learning environment needs to be redesigned around a series of synchronous and asynchronous student collaborative activities - this way both the in class and remote students actually benefit from an improved learning experience. This need not require technical support when students or student teams are tasked with creating solutions to synchronous and asynchronous collaboration - for example assigning students to stream segments of class interaction to remote students using a smartphone camera, remote students presenting projects live to the in-class students, creating a live video-conference for synchronous interaction between the in class students and the remote students, and designing asynchronous interaction via discussion forums, student sharing of recorded presentations, polling, peer feedback and marking.

The Scholarship of Technology Enhanced Learning (SoTEL), and a Design-Based Research (DBR) methodology (Educause Learning Initiative, 2012), can be used to guide the hybrid curriculum design process. This encompasses four stages: (1) being informed by the research literature, (2) designing a prototype task or activity, (3) evaluating the prototype task, redesigning it, and conducting further evaluation, (4) and refining and disseminating the task. A distributed learning community curriculum design model facilitates the potential to design creative student-generated projects as assessment activities for any course. Example hybrid online learning environment design scenarios in different discipline contexts may be (based upon the varied discipline expertise of the SIG members):

\section{Communications studies}

Model the professional use of social networks for short-form news critique and curation, through starting classes (or online sessions) with Twitter 'chats' critiquing a breaking event. These Twitter chats can be accessed and moderated in real-time via a second screen in the classroom or asynchronously via online students following an agreed Twitter Hashtag for the course. Twitter analysis tools can be used to gamify the chat through identifying top conversationalists or the tweets that generate the most interactions.

\section{STEM}

Highlight live synchronous integration of coding fragments for computer science, IT, or game design students using Blackboard Collaborate screen sharing and breakout groups to illustrate code integration and consequence. This would complement asynchronous coding videos highlighting theory and data structures provided to the learners using a flipped classroom approach. In this way the student cohort can steer the learning through the live practical demonstration by the expert educator or their peers through breakout groups, evidencing the flipped materials and digging deeper into the connection between syntax, data structures and code integration.

\section{Clinical Health}

Learners in clinical sciences can situate spatial anatomical structures and human systems using BYOD smartphones and augmented reality. Tools such as AR in Google search can assist the learner with spatial scale, surface level anatomy or human anatomical systems. An educator looking to begin a lesson into the digestive, endocrine, reproductive, nervous, lymphatic, integumentary, excretory, skeletal, muscular or circulatory stems could start the session with students searching for a term provided through online chat onto their smartphones and have students share photo content back to the online classroom. This not only engages the students, breaking the ice but also sets the spatial context for the lesson which would dig deeper into the surface level visualisation provided by the Google AR tool. 
creative design ideas and for the students to discuss. Debating their work in this manner allows students to feel more relaxed in Crits when showing their work and gives them the impression they were presenting in a much smaller group resulting in more confidence. Working in this way the students can become more comfortable in sharing their work rather than standing up in front of the entire studio class. Moving on past Covid-19 and back into the physical classroom requires a rethink of how we deliver our critiquing sessions and create a crossover of online and classroom sharing of students' designs and ideas.

\section{Performing and screen arts}

Assign students to stream segments of class performances to remote students using a smartphone camera and collaborative video application, remote students can also stream live performance back into the class, creating a live video-performance for synchronous interaction between the in-class students and the remote students.

\section{Teacher training}

Support groups of teachers (communities of practice) can be created to periodically share and discuss experiences of emergency remote teaching. Collaboratively made materials such as Google Slides can be created and viewed prior to a video conference in a way that models the flipped approach that many teachers are now adopting.

\section{Language learning}

After a period of rehearsal and practice both a teacher and her students can create and share short asynchronous language videos through the Flipgrid application. Subsequently, the teacher and students can interact with each other providing support, commentary and formative feedback either through further interlinked videos or text messages.

\section{Conclusions}

This concise paper explores the potential of collaborative curation and creation of resources by a group of educational technology practitioners to support online learning design during a crisis event that stretched the limits of support for a rapid move to online learning for academics who had little or no previous experience of online learning. Using a learner-centric ecology of resources to facilitate collaborative creation of resources models the practice that was preached, resulting in resources that were accessible to academics from a wide variety of digital literacy skillsets, with particular emphasis on practice-based learning environments in hybrid learning modes - or distributed learning communities as we prefer to conceptualise them.

\section{References}

Bower, M., \& Vlachopoulos, P. (2018). A critical analysis of technology-enhanced learning design frameworks. British Journal of Educational Technology, 49(6), 981-997. doi:10.1111/bjet.12668

Boyer, E. (1990). Scholarship reconsidered: priorities of the professoriate. Princeton, NJ: Carnegie Foundation for the Advancement of Teaching.

Crawford, J., Butler-Henderson, K., Rudolph, J., \& Glowatz, M. (2020). COVID-19: 20 Countries' Higher Education Intra-Period Digital Pedagogy Responses. Journal of Applied Teaching and Learning (JALT), 3(1). doi:10.37074/jalt.2020.3.1.7

Educause Learning Initiative. (2012). 7 Things You Should Know About Educational Design Research [Internet]. 7 Things You Should Know About... 2012(6 August). Retrieved from http://www.educause.edu/library/resources/7-things-you-should-know-about-educational-design- research

Haynes, D. (2016). Introducing SOTEL. International Journal for the Scholarship of Technology Enhanced Learning, 1(1), 1-2. Retrieved from http://ejournals.library.gatech.edu/ijsotel/index.php/ijsotel/article/view/17/14

Hodges, C., Moore, S., Lockee, B., Trust, T., \& Bond, M. (2020). The Difference Between Emergency Remote Teaching and Online Learning. Educause Review. Retrieved from https://er.educause.edu/articles/2020/3/thedifference-between-emergency-remote-teaching-and-online- learning

Laurillard, D. (2007). Pedagogical forms of mobile learning: framing research questions. In N. Pachler (Ed.), Mobile learning: towards a research agenda (pp. 33-54). London: WLE Centre, Institute of Education.

Laurillard, D. (2008). Technology Enhanced Learning as a Tool for Pedagogical Innovation. Journal of Philosophy of Education, 42(3-4), 521-533. doi:10.1111/j.1467-9752.2008.00658.x 
Laurillard, D. (2012). Teaching as a design science: Building pedagogical patterns for learning and technology. New York: Routledge.

Lowenthal, P., Borup, J., West, R., \& Archambault, L. (2020). Thinking Beyond Zoom: Using Asynchronous Video to Maintain Connection and Engagement During the COVID-19 Pandemic. Journal of Technology and Teacher Education, 28(2), 383-391. Retrieved from https://www.learntechlib.org/primary/p/216192/

Luckin, R. (2008). The learner centric ecology of resources: A framework for using technology to scaffold learning. Computers \& Education, 50(2), 449-462. doi:https://doi.org/10.1016/j.compedu.2007.09.018

Naciri, A., Baba, M. A., Achbani, A., \& Kharbach, A. (2020). Mobile learning in Higher education: Unavoidable alternative during COVID-19. Aquademia, 4(1), ep20016.

O'Donoghue, J. (2020). Irish teachers share their do's and don'ts of remote teaching. Education in Chemistry. Retrieved from https://edu.rsc.org/analysis/irish-teachers-share-their-dos-and-donts-of-remoteteaching/4011402.article

Puentedura, R. (2006). Transformation, Technology, and Education. Retrieved from http://hippasus.com/resources/tte/puentedura tte.pdf

Smith, E. (2020). 3 Things to Consider When Designing Remote Teaching.

Wickens, R. (2006). SoTEL: Toward a Scholarship of Technology Enhanced Learning. Canadian Journal of University Continuing Education, 32(2), 21-41. doi:https://doi.org/10.21225/D56300

Zayapragassarazan, Z. (2020). COVID-19: Strategies for Online Engagement of Remote Learners. F1000Research, 9. Retrieved from https://covid19.tabipacademy.com/wp- content/uploads/2020/05/COVID19-Strategies-for-Online-Engagement-of-Remote-Learners.pdf

Cochrane, T., Birt, J., Cowie, N., Deneen, C., Goldacre, P., Narayan, V., Ransom, L., Sinfield, D. \& Worthington, T. (2020). A collaborative design model to support hybrid learning environments during COVID-19. In Gregory, S., Warburton, S., \& Parkes, M. (Eds.), ASCILITE's First Virtual Conference. Proceedings ASCILITE 2020 in Armidale (pp. 84-89). https://doi.org/10.14742/ascilite2020.0119

Note: All published papers are refereed, having undergone a double-blind peer-review process.

The author(s) assign a Creative Commons by attribution licence enabling others to distribute, remix, tweak, and build upon their work, even commercially, as long as credit is given to the author(s) for the original creation.

(C) Cochrane, T., Birt, J., Cowie, N., Deneen, C., Goldacre, P., Narayan, V., Ransom, L., Sinfield, D. \& Worthington, $\mathrm{T}$. 